\title{
Identification of critical technology building blocks
}

\author{
Ravn, Poul Martin; Mortensen, Niels Henrik; Hvam, Lars
}

Published in:

Concurrent Engineering: Research and Applications

Link to article, DOI:

$10.1177 / 1063293 \times 17709050$

Publication date:

2017

Document Version

Peer reviewed version

Link back to DTU Orbit

Citation (APA):

Ravn, P. M., Mortensen, N. H., \& Hvam, L. (2017). Identification of critical technology building blocks.

Concurrent Engineering: Research and Applications, 25(4), 289-302 .

https://doi.org/10.1177/1063293X17709050

\section{General rights}

Copyright and moral rights for the publications made accessible in the public portal are retained by the authors and/or other copyright owners and it is a condition of accessing publications that users recognise and abide by the legal requirements associated with these rights.

- Users may download and print one copy of any publication from the public portal for the purpose of private study or research.

- You may not further distribute the material or use it for any profit-making activity or commercial gain

- You may freely distribute the URL identifying the publication in the public portal

If you believe that this document breaches copyright please contact us providing details, and we will remove access to the work immediately and investigate your claim. 


\title{
Identification of Critical Technology Building Blocks
}

\author{
Poul Martin Ravn ${ }^{\mathrm{a}}$, Niels Henrik Mortensen ${ }^{\mathrm{a}}$, Lars Hvam ${ }^{\mathrm{b}}$ \\ ${ }^{a}$ Dept. of Mechanical Engineering, Engineering Design and Product Development, Technical University \\ of Denmark; ${ }^{b}$ Dept. of Management Engineering, Operations Management, Technical University of \\ Denmark
}

\begin{abstract}
In order to have a better base for decisions, $R \& D$ managers need to know what the critical areas of development are in relation to the technologies they develop, mature, and include in the portfolio. As most of the technologies in a company have the potential to have a significant impact on competition, the challenge is to know how to identify and prioritize the development tasks. If possible, an effective strategy can be defined. This paper suggests a framework for identification and analysis of a product portfolio, with special emphasis on identifying critical technology building blocks based on reasoning about product properties. Current approaches lack such views and by focusing on these, potential make or break decisions are better supported. It is suggested to adopt the proposed framework to clarify where in the portfolio the technology needs critical attention for the next development steps. The framework is based on methods and theories in literature. The analysis of the portfolio is carried out through the framework in three steps: by creating an overview of the portfolio encompassing product and technology, assessing the elements in the overview with assessment metrics, and by using property chains to identify critical technology building blocks.
\end{abstract}

Keywords: technology development, technology building blocks, product properties, property reasoning, portfolio management

\section{Introduction}

In order to have a better base for decisions, $R \& D$ managers need to know what the critical areas of development are in relation to the technologies they develop, mature, and include in the portfolio. For large 
investments in technology the objectives are to reduce risk, whilst increasing performance (Mankins, 2009a). If successful, the potential output is breakthrough inventions (Ahuja and Lampert, 2001).

The challenge is to know how to identify and prioritize the development tasks as most of the technologies in a company have the potential to have a significant impact on competition (Porter, 1985). This requires an understanding of the technologies, but also knowledge of how to perform an assessment. Current approaches can be used to identify and prioritize technologies (Mankins, 2009a; Clausing and Holmes, 2010). However, these do not take the key properties of a product into account. The product properties have high relevance in the assessment and positioning of a novel technology in a portfolio as these often are used for comparing whether a technology is competitive against other technologies. Therefore, the focus should be on properties and the link to the elements of technologies that carry these.

In this paper elements of technology are referred to as Technology Building Blocks (TBB). These are knowledge areas formed around natural phenomena and principles and with an acknowledgement of the fact that a producing firm must consider two dimensions of a technology: a product dimension (the principle of how to harness a natural phenomenon) and the production dimension (the transformations related to the making of the principle) (Mørup, 1993; Greis, 1995). In the simplest form, technology is a phenomenon captured and put to use (Arthur, 2009). This understanding thus accepts coherence between product and production technology. Therefore, in this paper the TBBs can represent both product technologies and production technologies. A specific type of TBB is of key interest and emphasis in this paper: the Critical Technology Building Block (CTBB). We define CTBBs as those essential for increasing key product properties. This meaning that an increase in knowledge of a CTBB is crucial to increase a product property and will affect this product property positively through a focused development effort. If the CTBBs cannot be identified and targeted, there is little indication of what should be focused on in the development to increase a certain property, and therefore a higher risk of making wrong strategic decisions that may result in time and cost overruns. 
A three-step framework is proposed for the identification of CTBBs. Step one: create an overview of the forming portfolio for the company. Step two: assess the contents of the portfolio. Step three: use property reasoning to identify CTBBs by use of chains through the portfolio.

\subsection{Challenges identified in literature}

The following challenges in relation to technologies, development, and strategy have been found in the literature:

(1) By splitting technology development and product development in the organization, there is a risk of inefficient transfer of technology and lack of synchronization (Wood and Brown, 1998; Lakemond et al., 2007; Nobelius, 2004; Holt, 1991).

(2) A large part of the value chain may have to be developed from scratch when a novel technology is used for definition of new products (Wood and Brown, 1998; Tryson and Kiil, 2010).

(3) There are disconnects between the strategies of the business and where the money is spent (Cooper et al., 2001).

(4) Resources need to be spent with the best possible chance of progression on the right tasks (Mankins, 2009a).

(5) Increasingly high level of complexity and high level of technical novelty in products affect technology integration (Iansiti, 1995).

(6) There is a high dependence on the competence and the initiative of individual managers and engineers (Holt, 1991; Mankins, 2009b).

\subsection{Requirements for a framework}

Based on both the challenges found in literature, as well as the current need situation in a large-scale technology development project, requirements were formed for the proposed framework.

The purpose of the framework is: 
- To identify a uniform structure describing the product portfolio, including technology building blocks, and including different levels of the value chain to allow overview of all entities to form the best basis for decisions (related to (1) and (2)).

- To enable an assessment of the portfolio and development status. (related to (5) and (6)).

- To provide a basis for strategic decisions of what products and technologies should be focused upon (related to (3) and (4)).

A framework for identification of CTBBs should enable R\&D managers to:

- Identify a structure that can describe the relation between the products and technologies in the company portfolio, as technologies are developed with an intended use in an organization.

- Assess the development, as it is critical for senior management to be able to choose between alternatives (Mankins, 2009a).

- Trace product properties through the value chain, as these are key to positioning on the market (Mørup, 1993).

- Identify the technologies that are the main contributors to the next level of performance within a certain property, as these can be defining for the technology strategy.

\subsection{Structure of the paper}

First, the research methodology is introduced followed by a state of the art review. Then the framework is introduced, and an example is given of the use. Field testing of the framework is presented by using an industry example of the Dielectric Electro-Active Polymer (DEAP) technology development project. Finally, the discussion and conclusion make up the final sections of the paper.

\section{Methodology}

The Design Research Methodology (DRM) approach was used, from Research Clarification (RC) to initial Descriptive Study II (DS-II) (Blessing and Chakrabarti, 2009). 
Literature study: A literature study was conducted in two parts: state of the art within modelling approaches and theoretical base for the framework. Literature was gathered over two iterations: a broad, initial iteration followed by a more detailed search. Here, the abstracts were read and papers of interest were included in the literature study.

Building of the framework: The base skeleton of the framework was created, based on literature. Literature on product structure relations and product/technology relations was used for the first step of the framework. Literature on assessment metrics was used for the second step, and literature on product properties, property reasoning, and engineering design, was used for the third step.

Testing and evaluating the framework: A concluding, four-year, $13 \mathrm{M} €$, industrial project was used to test the framework. Data was collected from multiple sources: a joint data repository for 10 work packages, individual repositories, meetings, and through informal interviews. The framework was tested to verify fulfilment of the requirements. Finally, an evaluation of the framework was made in a workshop by four key persons from the industry project.

\section{State of the art}

The state of the art is focused on four main areas based on the requirements for a framework: how to capture attributes of a system, i.e. structure and behaviour of a system, single and multi-product development, how to include technology, and how to assess and prioritize development tasks.

\subsection{Structure and behaviour of a product system}

A product system can be described from two perspectives, the structural characteristics (structure) and the functional properties (behaviour) (Andreasen et al., 2014).

\subsubsection{Structure of a product system}

In design structure matrix (DSM) (Steward, 1981) approaches, products are decomposed into smaller components or systems with relations between these indicated. Ordinary DSMs are used to decompose and relate parts, requirements, processes etc., for instance as proposed by Eppinger and Browning (2012) and 
Bonev et al. (2013), and can represent different levels of a system (Tilstra et al., 2012), or to indicate product variety (Luh et al., 2011). Furthermore, DSMs can be used for clustering (Daie and Li, 2016) and complex product architecture analysis (Uddin et al., 2016). Quality Function Deployment (QFD) is used to convert customer demands into engineering requirements. Modular Function Deployment (MFD) is used with module drivers to view the flow and refinement from customer demands to designed modules (Nilsson and Erixon, 1998). The product family master plan (PFMP) (Harlou, 2006) is used to map structure from three points of view and the relations between these: customer, product, and production. Bonev et al. (2013) combined the matrix approach with the PFMP in the Product Requirements Development Model to investigate the effect of requirements on the product architecture.

\subsubsection{Behaviour of a product system}

The behavioural view of a system is here divided into functions and properties. Function diagrams give a function structure with sub-functions connected by energy, material, and energy flows (Ulrich and Eppinger, 2008). Both Function-Behaviour-State (Tomiyama et al., 1993) and Function-BehaviourStructure (Gero, 1990) apply function modelling to reason about products. Organ diagrams have been used to model the "organs" of a product (Harlou, 2006). More recently, the organ diagram has evolved to accommodate switching between different system views (Bruun et al., 2014).

Function and property reasoning are found with a sound base in engineering design (Gero, 1990; Howard and Andreasen, 2013; Vermaas, 2013). Andreasen et al. (2014) contributed with the articulation of the Domain theory and the link-model where the latter specifically can be applied for reasoning about functions and properties of both the product and the use activity. Property reasoning and property modeling (Andreasen et al., 2015) provide insight into the background for this type of mind-set approach with a description of property decomposition patterns to allow an identification of properties or qualities of subsystems (Mørup, 1993). Jensen et al. (2015) used property models to decouple interrelated dependencies to enable carry-over of test documentation between product families. In the Characteristics-Properties Modelling (CPM) and Property-Driven Development/Design (PDD), a distinction is also made between the characteristics and the properties of a product (Weber and Deubel, 2003; Weber, 2005). 


\subsection{Single and multi-product}

For large, single systems UML or SysML modelling languages can be used to describe the system of interest and the interaction between different views on the system, often based on the construction of meta-models (Andersson et al., 2010). To simplify the, at times, large system descriptions, Borches (2010) proposed the A3 overview on which a single page is used to represent the system in focus to have a manageable architectural representation (Bonnema et al., 2010).

For multi-product development the program architecture approach aims to optimize the product portfolio by mapping the program architecture, consisting of market, product, and production architectures (Hansen, 2014). The integrated PKT-approach aims to achieve external product variety for the market with small internal variety of components and processes in the company (Krause et al., 2014). The Brown-field process contributes with a design process to modular product family development via design information elements (Pakkanen, 2015).

\subsection{Including technology}

When looking into literature, different understandings and classifications of technology and technology development can be found (Burgelman et al., 2009; Fusfeld, 1978; Högman et al., 2010; André et al., 2014). Dosi (1982) argued that physical devices embody the achievements in the development of a technology in a defined problem-solving activity. Meyer and Lehnerd (1997) included product and production technologies as a base for product platforms. Thus, a producing firm must consider two dimensions of a technology: a product dimension (the principle of how to harness a natural phenomenon) and the production dimension (the transformations related to the making of the principle) (Mørup, 1993; Greis, 1995). Schulz et al. (2000) see Process Technologies, together with Management \& Organisation and Methods and Tools, as secondary technologies that enable product technologies (primary technologies).

Different approaches are found to include technology indicating the thoughts of structure and the application of technology. Bitzer et al. (2014) discuss Technology Objects and Jeong \& Yoon (2014) utilize 
an ontology of technology for structure. Huang et al. (2011) utilize R\&D to applications cross-chart to connect technology and application.

Platforms have also been used at a technology level, i.e. technology platforms, where models and frameworks have been presented with definitions and descriptions of relations to product platforms (Levandowski et al., 2012; Simpson et al., 2014; Nasiriyar, 2009; Nasiriyar et al., 2010; Wonglimpiyarat, 2004; Kristjansson et al., 2004).

\subsection{Prioritizing and assessing tasks}

Roadmapping is a widely used tool to prioritize and relate time-dependent task-deliveries (Ulrich and Eppinger, 2008). It is used to map out and prioritize deliveries from projects, departments, tasks etc., and indicate the relations to a recipient. The number of levels of coordination can vary by project type (Mortensen et al., 2005). Vojak et al. (2004) proposed a methodology to investigate possible disruptive technologies. Zurcher and Kostoff (1997) provided an approach to model technology roadmaps. Jeong and Yoon (2014) presented patent roadmapping and the relation to technology roadmaps. Technology roadmapping has also been used as a method for technology push (MTP) (Caetano and Amaral, 2011) and as a model for disruptive technology (Walsh, 2004).

For measuring technology, a main classification can be made for a given technology to deliver its function (related to product), and to be produced (related to production) (Williamson and Beasley, 2011). In order to assess systems under development, Mankins (2009a, 2009b) suggested technology-centric measures with the technology readiness levels (TRL), technology need value (TNV), and research and development degree of difficulty (R\&D^3). Clausing and Holmes (2010) proposed the technology readiness assessment (TRA) matrix. In the early phases also integration readiness level (IRL) and system readiness level (SRL) can also be considered (Sauser et al., 2008). In relation to process or manufacturing-related context, two main assessment methods can be considered: manufacturing readiness level (MRL) and manufacturing capability readiness level (MCRL) (OSD Manufacturing Technology Program, 2015; Ward et al., 2012). 


\subsection{A need for a different approach}

When comparing with the requirements posed for the framework in section 1.2, the following is argued. Few of the presented modelling approaches focus on the handling of discussions evolving around the technology-based choices needing to be taken in the development. Only a few frameworks and methodologies include reasoning about properties in a holistic manner and include technology. Concluding the review, a framework to use as a basis for taking decisions on further development with focus on technology, based on property reasoning, is absent.

\section{Framework for identification of critical technology building blocks}

In the following sections the three steps for the framework are introduced.

\subsection{The framework: overview, assessment, and reasoning}

The framework is formed of the three main steps:

- Step 1: Creating the portfolio overview - where the base structure is described on multiple tiers.

- Step 2: Assessing the system elements - where the contents of the overview are assessed.

- Step 3: Reasoning about properties - where the desired properties are projected down through the portfolio overview.

Where the first two steps are used to create an overview with metrics of the current portfolio development status, emphasis is put on the third step with identification of CTBBs by use of key product properties.

The combination of the three steps will provide a structured way of representing the technologies and capabilities in the company as well as providing a sound base for a technology strategy definition. Inputs and outputs can be seen in Table 1.

Table 1 around here 


\subsection{Step 1: Building an entity-relation overview of the product portfolio including technology}

The main structure of the overview is split into two main dimensions: product and technology and follows a diabolo structure (Erens, 1996), as illustrated in Figure 1. The structure is linked to the granularity view of a product and the tiers get input from each other. A part of the overview can be singled out, with the greyed-out structure, in order to focus on parts of the development.

Figure 1 around here

Reading from the bottom of a tier the technologies are represented by TBBs. These are realized in components. The components (here referred to as modules, organs, and parts (Meyer and Lehnerd, 1997; Gershenson et al., 2003; Andreasen, 2011)) make up a product family (a group of related products (Simpson et al., 2006)), based on an architecture aimed at a specific market. These related products are in the framework illustrated as variants. Modeling the entity-relation overview may be done with the preferred tool of the framework user.

In the overview products platforms can be made out of components (Meyer and Lehnerd, 1997), albeit not being the main focus. Likewise technology platforms can be indicated in the technology dimension. The top tier of an overview represents the end user product in which the technology is integrated. This tier is also the starting point for the last framework step, the Reasoning.

\subsection{Step 2: Assessing the current situation in the portfolio}

The assessment is used to give knowledge on the status of the development in the overview. For each of the elements, the completed development tasks are represented. This will give an indication to the project management to illustrate the status of each element. Additionally, performance metrics are indicated here (Mankins, 2009a). A number of assessment metrics for technologies were identified in Section 3.4. Each of them enables assessment of technologies in the product or production dimensions. The identified assessment metrics are illustrated in Table 2 with their respective scales.

Table 2 around here 
The assessment metrics compared in Table 2 can be used based on the preference of the company, project, or person set with the task of mapping out and assessing the portfolio. No preference of a specific assessment metric is given in this paper. However, the crucial part is to agree on the use of the same metric company-wise to enable a uniform and comparable assessment of the current situation in the portfolio. For effectiveness, a consistent identification of the technologies is needed, i.e. naming, description of its characteristics, etc. (Mankins, 2009a).

Consider a completed assessment illustrating different readiness levels. An argument can be made to target the entities in the portfolio scoring the lowest readiness. The assessment metrics in the overview will provide the current situation of the portfolio, development-wise, but will not give an indication of what to develop next to create value for the potential customer. For this, reasoning about the product properties is needed as a third step in the framework.

\subsection{Step 3: Property reasoning to identify critical technology building blocks}

The third step is based on an understanding of product properties to identify CTBBs. A user of a product determines its value through product properties, which are realized through its deployment (Andreasen et al., 2015). A product realizes multiple properties however a limited number of these are of value to the user, identified as key properties. Key properties can be identified by market analysis, user analysis, competitor analysis, or changing requirements, such as legal requirements or standards. An understanding of the key properties of the products in the portfolio is needed for a company to be competitive.

Property decomposition can be made to determine in what entities properties are determined by characteristics (Andreasen et al., 2015; Jensen et al., 2015). Adding to the understanding of property decomposition, we define two types of decomposition patterns for properties. These are, as illustrated in Figure 2: Property Delivery Chain (PDC) defined as a bottom-up pattern and Property Target Chain (PTC) defined as a top-down pattern. PDCs track the deliveries made based on the solutions chosen. One solution may contribute with multiple properties. PTCs are used in this step to track properties down to CTBBs.

Figure 2 around here 
The task of identifying the PTC for a certain property starts from the top tier. Here the properties, guided by requirements for instance are found. The requirements are considered for the product domain (Prasad, 2002). These are transformed to product property requirements for the lower tiers, based on decomposition of the requirements. This means that the property reasoning is driven by an understanding and decomposition of requirements. As the PTCs are gradually completed, they will end up at entities in the portfolio, that through their characteristics greatly contribute to the property.

The property reasoning step of the framework presupposes a deep knowledge and matter insight into products in the portfolio. Understanding the relation between properties and characteristics will assist the reasoning in this step as the characteristics that define the components play a role in the definition of the properties. The main reasoning is made by setting a number of requirements that guide the identification of the CTBBs.

\subsection{Example of using the framework}

Consider the following example of a badminton racket manufacturer. A competitor has introduced a new type of frame obtaining better racket frame flexibility. The manufacturer wants to introduce a new type of frame to stay competitive. Step 1-3 could be as illustrated in Figure 3.

Figure 3 around here

Step 1 presents four tiers of granularity from the badminton racket (tier 4), through frame (tier 3), and down to shaft (tier 2) and material (tier 1) as these are related to the frame. A newly developed shaft (part of the frame) is shown to illustrate the assessment (Figure 3, middle). It is based on a new shaft core material. The shaft is evaluated in different dimensions, and the completed development tasks noted.

The frame from the competitor offers more power to the players in their shots. The value proposition that needs to be focused upon is linked to the property "Flexibility" for the racket shaft. By trailing the PTC (Figure 3, right) the shaft core technology is identified to be the CTBB in the portfolio for the flexibility property. 
Having introduced the framework and given an example of the use, the next section will introduce experiences from field testing the framework.

\section{$5 \quad$ Field testing in a technology push setting}

A test of the framework was made in an industrial project to verify the applicability of the three framework steps. The industrial project was in a technology push setting, where a technology was investigated towards a future commercialization, and therefore with an initial suggestion to a forming portfolio. The project was a technology development project in the stages before system development projects (Mankins, 2009a).

\subsection{The situation - development on all fronts}

A spin-out company aimed to commercialize the DEAP technology based on a patent (Tryson and Kiil, 2010). The DEAP technology had the potential for multi-industry application as a transducer sub-system (actuator, generator, or sensor). The development included a substantial part of the value chain (Tryson and Kiil, 2010), ranging from the core polymer material, through the transducer concept definition, and over to testing of the product concepts in four industrial applications (Sarban and Guðlaugsson, 2013).

There was a need to lay out and display the portfolio forming around the DEAP technology on multiple tiers to enable strategic decisions for further development. Overviews had until then been to a degree implicit, resulting in a fragmented and incomplete overview of the development tasks.

\subsection{Step 1 and 2: Identifying and assessing the portfolio structure on multiple levels}

The core technology for a DEAP transducer is the EAP technology. This example is concentrated on only a partial view of the full overview, i.e. the electrical driver for the DEAP transducer was not included as the main properties of the DEAP product were found in the transducer (Tryson and Kiil, 2010). The overview levels followed the proposed main structure of Step 1, as well as the levels of the project, i.e. on $\mathrm{T} 1$, the polymer material, on $\mathrm{T} 2$ the EAP film, on T3 the DEAP transducers, and on T4 the applications, as seen in Figure 4.

Figure 4 around here 
Due to project confidentiality, the overview has been simplified in this example. The basic overview was based on data found in the joint project data repository, individual repositories, meetings, and through informal interviews. The data types were technical reports (repositories and meetings), overview descriptions, in presentations (repositories and meetings) for example, and relational descriptions (meetings and interviews). The overview was made by the researchers in collaboration with participants of the work packages. By proposing structures and relations, discussions were found to initiate on what implications the previous decisions had created.

As the main focus for the development was on tiers 1-3 in the development, tier 4 had a higher abstraction level. On the 4th tier, the applications, architecture models were used for documenting the relations in four technology prototypes, i.e. prototypes built for assessment of performance of the DEAP transducers in a product concept formulated with the application companies (Ravn et al., 2015).

In the project, the assessments of the portfolio elements (Step 2) were conducted by describing completed development tasks and by using TRL as a performance measure (see Figure 4).

\subsection{Step 3: Property reasoning to identify property target chain}

From the top down, the PTC reasoning, a number of key properties were used from the development up until that point in time. The properties were based on lessons learned through the three development cycles in the four prototype applications, as well as analysis of competing technologies on the market. The properties were then guided down through the overview and for each level a set of requirements was discussed by the project participants, based on the implication the increase of property would have on that specific element on that specific tier.

Two PTCs are illustrated in Figure 5. The properties high force density and high dynamic movement had been identified as key properties on tier 4 .

Figure 5 around here

For the first example, a high force density was sought as a value proposition. From here, guiding requirements were used to facilitate the property decomposition represented by the PTC. The PTC was 
tracked through a specific product family entity on tier 3, down to a CTTB A on tier 2 and a CTBB B on tier 1. CTBB A was related to the electrode deposited on the polymer film and CTBB B was related to the material composition technology.

For the second example, a high dynamic was sought as a value proposition. The PTC was tracked through a specific product family entity on tier 3 , down to a CTBB B on tier 1 - the material composition technology. Having identified the CTBBs, the following discussion covered the next action steps:

- The material (critical technology building block B) should be approached with a platform segmentation in the next development task. Thereby different requirements could be fulfilled instead of a "fits all" material. By making different material platforms, performance increase was expected.

- The electrode (critical technology building block A) should look to be improved if the goals of durability and robustness were to be achieved.

As an output from the framework, prioritization of resource allocation and identification and specification of action steps were made possible.

\subsection{Specialist evaluation of the framework}

A workshop was held with project decision makers and specialists, including the CTO, project managers, and steering committee members, to evaluate the framework. The following was articulated about the value of the framework:

- "I realize that some tasks form around a whole new technology by themselves."

- "The framework is really strong for cutting to the bone for the next step (of development)."

- "We need to discuss whether some technologies are product or production related."

- "The framework is best suited for a top-down approach."

- "For the technological decisions, we now have an idea of where to focus." 
- "By tracking the value propositions we can see the impact."

The statements indicate that the participants, albeit their deep knowledge about the technology on the different tiers, evaluated the framework as being useful for creating a good base for decisions.

\subsection{Summarizing the use of the framework}

With the field testing case, it has been illustrated that the framework fulfilled the purposes to: a) identify a uniform structure over multiple value chain levels, b) enable assessment of the portfolio and development status, and c) provide basis for strategic decisions.

It was found that the overview in step 1 could be used to describe the structure of the four tiers and the relations between these, as well as describing the relations between the product dimension and technology dimension. Using assessment in step 2 gave the status of the development and step 3, with the use of two examples, was illustrated to enable an identification of CTBBs on different levels of the value chain by use of PTCs.

\section{Discussion}

Compared to other approaches, such as the ones mentioned in Section 3, the proposed framework includes to a higher degree, the technologies in the company. Rather than having product optimization in focus, the framework is focusing on the inclusion of technology building blocks and specifically targeting CTBBs by the use of PTCs. This, combined with the aforementioned approaches, seeks to support the definition of a viable and sound development strategy.

\subsection{Fulfilling the requirements}

The framework provides a holistic approach to viewing the portfolio including technologies under development and provides the means to navigate in the development. With the field test it was illustrated that the framework fulfilled the purposes from Section 1.2. The example and field testing illustrated that the framework was able to include multiple tiers, allowing assessment, as well as successful identification 
of CTBBs. This speaks of fulfilment of the requirements for the framework. Additionally, the challenges from Section 1.1 are addressed in the framework. The overview allows for identification of the relations between the entities in the portfolio and thus bringing transparency for management. The assessment enables a status to be given to each of the entities being developed. The reasoning enables identification of the critical areas for key performance.

\subsection{Evaluation of research}

The research presented in this paper has a natural limit with it being tested on a single case. However, it is assessed to be representative for other companies trying to establish a portfolio based on a novel technology. The validation of the framework is preliminary and further testing is needed for increased insight into the identification of critical technology building blocks. A number of assumptions were made for the framework. It was assumed that for both technology push and market pull settings, potential products in which the technology can be used are identified. Therefore, another assumption is that the potential products are known. As the framework uses input from possible applications already identified, the selection of applications was not covered in this paper. Future research may include the coupling between the framework and pairing with possible applications.

\subsection{Additional case observations}

It was found that terminology had a large impact, both in the theoretical and practical models, as technology is individually interpreted. The preparatory work needed to create consensus on the elements and relations

in the overview can be a large task, and should be undertaken by an architecture and platform department or alike for maximum communication throughout an organization.

In the lower tiers of the overview it became harder to apply the framework structure. This may be due to reaching a level where the components are closer to natural phenomena and basic materials.

At the beginning of the industrial case it was a major challenge for the different development teams when needing to keep the overview. Ten work packages had to coordinate and cooperate towards common goals, so that ideas and decisions, and ultimately the overall strategy were in alignment. 


\subsection{Application in incremental and radical innovation}

The framework presented in this paper was presented through the use of (a) a case of a demand pull setting for a badminton racket manufacturer with existing products, and (b) a field testing in a technology push setting for the DEAP technology with no existing products, but prototypes instead. The main findings are represented with the latter case of a company trying to establish a portfolio based on a novel technology. The rationale in the steps of the framework is however not limited to fundamentally new products but may also be applicable for incremental improvements to existing products (Ulrich and Eppinger, 2008), where the identification of CTBBs can help guiding the development as well as definition of product roadmaps for variants and sub-system innovations.

\section{Conclusion}

In this paper a framework was presented to provide a structured way of analyzing a product portfolio to identify Critical Technology Building Blocks (CTBBs) that enable prioritization of the development. The three-step framework consisted of: the creation of an overview, assessment of the elements in the overview, and finally the use of Property Target Chains (PTCs) to enable identification of CTBBs. The contents of the framework have been devised from literature, described and a general example was used to describe the general approach and method to using the framework. The framework was tested in an industrial technology development project in which transducers based on the DEAP technology were built and tested. The framework has the potential to increase the efficiency of $R \& D$, as application specialists evaluated the framework to be a strong framework for cutting to the key focus of the development. Further research should be used to investigate the use dimensions of the framework in other settings and to validate on a broader scale. Further work will include testing on additional projects to validate the findings.

\section{Acknowledgements}

The authors would like to thank the participants of the industry project. The work was financially supported by Innovation Fund Denmark. 


\section{References}

Ahuja G and Lampert CM (2001) Entrepreneurship in the Large Corporation: A Longitudinal Study of How Established Firms Create Breakthrough Inventions. Strategic Management Journal 22 (6-7): 521-543. doi:10.1002/smj.176.

Andersson H, Herzog E, Johansson G et al. (2010) Experience from Introducing Unified Modeling Language/Systems Modeling Language at Saab Aerosystems. Systems Engineering 13 (4): 369-380. doi:10.1002/sys.20156.

André S, Stolt R, Elgh F et al. (2014) Managing Fluctuating Requirements by Platforms Defined in the Interface Between Technology and Product Development. In Moving Integrated Product Development to Service Clouds in the Global Economy, edited by J. Cha, 424-433. IOS Pres. doi:10.3233/978-1-61499-440-4-424.

Andreasen MM (2011) 45 Years with Design Methodology. Journal of Engineering Design 22 (5): 293332. doi:10.1080/09544828.2010.538040.

Andreasen MM, Hansen CT and Cash P (2015) Conceptual Design: Interpretations, Mindset and Models. 1st ed. Springer International Publishing Switzerland. doi:10.1007/978-3-319-19839-2.

Andreasen MM, Howard TJ and Bruun HPL (2014) Domain Theory, Its Models and Concepts. In An Anthology of Theories and Models of Design: Philosophy, Approaches and Empirical Explorations, edited by Amaresh Chakrabarti and Lucienne T.M. Blessing, 173-195. Springer. doi:10.1007/9781-4471-6338-1_9.

Arthur WB (2009) The nature of technology: What it is and how it evolves. Free Press

Bitzer M, Vielhaber M and Dohr F (2014) From Product Development to Technology Development. In 24th CIRP Design Conference, 21:247-251. Elsevier B.V. doi:10.1016/j.procir.2014.03.140.

Blessing LTM and Chakrabarti A (2009) DRM, a Design Research Methodology. Springer. doi:10.1007/978-1-84882-587-1.

Bonev M, Wörösch M, Hauksdóttir D et al. (2013) Extending Product Modeling Methods for Integrated Product Development. In Proceedings of the International Conference on Engineering Design, ICED, 219-228. Seoul.

Bonnema GM, Borches PD, Kauw-A-Tjoe RG et al. (2010) Communication: Key Factor in Multidisciplinary System Design. In 8th Conference on Systems Engineering Research. Hoboken, NJ, USA: CSER.

Borches PD (2010) A3 Architecture Overviews - A Tool for Effective Communication in Product Evolution. PhD Diss., University of Twente.

Bruun HPL, Mortensen NH and Harlou U (2014) Interface Diagram: Design Tool for Supporting the Development of Modularity in Complex Product Systems. Concurrent Engineering 22 (1): 62-76. doi:10.1177/1063293X13516329.

Burgelman RA, Christensen CM and Wheelwright SC (2009) Strategic Management of Technology and Innovation. Fifth. McGraw-Hill.

Caetano M and Amaral DC (2011) Roadmapping for Technology Push and Partnership: A Contribution for Open Innovation Environments. Technovation 31 (7): 320-335. doi:10.1016/j.technovation.2011.01.005.

Clausing D and Holmes M (2010) Technology Readiness. Research Technology Management 53 (4): $52-$ 59.

Cooper RG, Edgett SJ and Kleinschmidt EJ (2001) Portfolio Management for New Products. Basic Books.

Daie P and Li S (2016) Matrix-based hierarchical clustering for developing product architecture. Concurrent Engineering 24 (2): 139-152. doi:10.1177/1063293X16635721.

Dosi G (1982) Technological Paradigms and Technological Trajectories - A Suggested Interpretation of the Determinants and Directions of Technical Change. Research Policy 11 (3): 147-162. doi:10.1016/0048-7333(82)90016-6.

Eppinger SD and Browning TR (2012) Design Structure Matrix Methods and Applications. The MIT Press. 
Erens F-J (1996) The Synthesis of Variety - Developing Product Families. PhD Diss., Eindhoven University of Technology.

Fusfeld AR (1978) How to Put Technology into Corporate Planning. Technology Review 80 (6): 51-55.

Gero JS (1990) Design Prototypes: A Knowledge Representation Scheme for Design. AI Magazine 11 (4): 26-36.

Gershenson JK, Prasad GJ and Zhang Y (2003) Product Modularity: Definitions and Benefits. Journal of Engineering Design 14 (3): 295-313. doi:10.1080/0954482031000091068.

Greis NP (1995) Technology Adoption, Product Design, and Process Change: A Case Study in the Machine Tool Industry. IEEE Transactions on Engineering Management 42 (3): 192-202. doi: $10.1109 / 17.403737$.

Hansen CL (2014) On the Identification of Architectures for Product Programs. PhD Diss., Technical University of Denmark.

Harlou U (2006) Developing Product Families Based on Architectures: Contribution to a Theory of Product Families. PhD Diss., Technical University of Denmark.

Holt K (1991) Technology Strategy - Is There a Need for It? Journal of Engineering Design 2 (2): 105-112.

Howard TJ and Andreasen MM (2013) Mind-Sets of Functional Reasoning in Engineering Design. Artificial Intelligence for Engineering Design, Analysis and Manufacturing: AIEDAM 27 (3): 233240. doi:10.1017/S0890060413000231.

Huang L, Guo Y, Peng Z et al. (2011) Characterising a Technology Development at the Stage of Early Emerging Applications: Nanomaterial-Enhanced Biosensors. Technology Analysis \& Strategic Management 23 (5): 527-544. doi:10.1080/09537325.2011.565666.

Högman U, Bengtsson D, Stetz S et al. (2010) Requirements on New Technology and the Technology Implementation Process. Proceedings of NordDesign. Sweden.

Iansiti M (1995) Technology Development and Integration : An Empirical Study of the Interaction Between Applied Science and Product Development. IEEE Transactions on Engineering Management 42 (3): 259-269. doi:10.1109/17.403744.

Jensen TV, Parslov JF and Mortensen NH (2015) ENABLING REUSE OF DOCUMENTATION IN NEW MEDICAL DEVICE DEVELOPMENT: A SYSTEMATIC ARCHITECTING APPROACH. In Proceedings of ASME IDETC/CIE, 1-12. Boston, MA, USA.

Jeong Y and Yoon B (2014) Development of Patent Roadmap Based on Technology Roadmap by Analyzing Patterns of Patent Development. Technovation 39-40: 1-16. doi:10.1016/j.technovation.2014.03.001.

Krause D, Beckmann G, Eilmus S et al. (2014) Integrated Development of Modular Product Families: A Methods Toolkit. In Advances in Product Family and Product Platform Design, edited by Timothy W Simpson, Jianxin Roger Jiao, Zahed Siddique, and Katja Hölttä-Otto, 245-269. Springer New York. doi:10.1007/978-1-4614-7937-6.

Kristjansson AH, Jensen T and Hildre HP (2004) The Term Platform in the Context of a Product Developing Company. Design 2004: Proceedings of the 8Th International Design Conference: 325 - 330.

Lakemond N, Johansson G, Magnusson T et al. (2007) Interfaces between Technology Development, Product Development and Production: Critical Factors and a Conceptual Model. International Journal of Technology Intelligence and Planning 3 (4): 317-330.

Levandowski CE, Corin-Stig D, Bergsjo D et al. (2012) An Integrated Approach to Technology Platform and Product Platform Development. Concurrent Engineering 21 (1): 65-83. doi:10.1177/1063293X12467808.

Luh D-B, Ko Y-T and Ma C-H (2011) A Structural Matrix-Based Modelling for Designing Product Variety. Journal of Engineering Design 22 (1): 1-29. doi:10.1080/09544820902877591.

Mankins JC (2009a) Technology Readiness and Risk Assessments: A New Approach. Acta Astronautica 65 (9-10): 1208-1215. doi:10.1016/j.actaastro.2009.03.059.

Mankins JC (2009b) Technology Readiness Assessments: A Retrospective. Acta Astronautica 65 (9-10) (November): 1216-1223. doi:10.1016/j.actaastro.2009.03.058. 
Meyer MH and Lehnerd AP (1997) The Power of Product Platforms : Building Value and Cost Leadership. The Free Press.

Mortensen NH, Harlou U and Andreasen MM (2005) Identification of Platform Levels in Product Development. In International Conference on Engineering Design. Melbourne: Design Society.

Mørup M (1993) Design for Quality. PhD Diss., Technical University of Denmark.

Nasiriyar M (2009) Economics of Innovation and New Technology. Economics of Innovation and New Technology Vol. 5- (1 (768307933): 1-29. doi:10.1080/10438590500512927.

Nasiriyar M, Nesta L and Dibiaggio L (2010) Technological Assets as Platforms for Business Diversification. Opening Up Innovation: Strategy, Organization and Technology.

Nilsson P and Erixon G (1998) The Chart of Modular Function Deployment. In Proceedings of the 4th WDK Workshop on Product Structuring, 147-154. Delft, Netherlands.

Nobelius D (2004) Linking Product Development to Applied Research: Transfer Experiences from an Automotive Company. Technovation 24 (4): 321-334. doi:10.1016/S0166-4972(02)00073-1.

OSD Manufacturing Technology Program. (2015). Manufacturing Readiness Level (MRL) Deskbook Version 2.4.

Pakkanen J (2015) Brownfiels Process - A Method for the Rationalisation of Existing Product Variety towards a Modular Product Family. PhD Diss., Tampere University of Technology.

Porter ME (1985) Technology and Competitive Advantage. Journal of Business Strategy 5 (3): 60-78. doi:10.1108/eb039075.

Prasad B (2002) Building blocks for a decision-based integrated product development and system realization process. Systems Engineering 5 (2): 123-144. doi:10.1002/sys.10008.

Ravn PM, Gudlaugsson TV and Mortensen NH (2015) A Multi-Layered Approach to Product Architecture Modeling: Applied to Technology Prototypes. Concurrent Engineering. doi:10.1177/1063293X15590843.

Sarban R and Guðlaugsson TV (2013) Platform Based Design of EAP Transducers in Danfoss PolyPower $A / S$. Proceedings of the SPIE - the International Society for Optical Engineering 8687.

Sauser B, Ramirez-Marquez JE, Magnaye R et al. (2008) A Systems Approach to Expanding the Technology Readiness Level within Defense Acquisition. International Journal of Defence Acquisition Management 1: 39-58.

Schulz AP, Clausing DP, Fricke E et al. (2000) Development and Integration of Winning Technologies as Key to Competitive Advantage Systems Engineering 3 (4): 180 - 211.

Simpson TW, Jiao JR, Siddique Z et al (2014). Advances in Product Family and Product Platform Design. doi:10.1007/978-1-4614-7937-6.

Simpson TW, Siddique Z and Jiao JR (2006) Platform-Based Product Family Development. In Product Platform and Product Family Design, edited by Timothy Simpson, Zahed Siddique, and Jianxin Roger Jiao. Springer Science+Business Media.

Steward DV (1981) The Design Structure System: A Method for Managing the Design of Complex Systems. IEEE Transactions on Engineering Management 28 (3): 71 - 74.

Tilstra AH, Seepersad CC and Wood KL (2012) A High-Definition Design Structure Matrix (HDDSM) for the Quantitative Assessment of Product Architecture. Journal of Engineering Design 23 (10-11): 767-789. doi:10.1080/09544828.2012.706748.

Tomiyama T, Umeda Y and Yoshikawa H (1993) A CAD for Functional Design. CIRP Annals Manufacturing Technology 42 (1): 143-146. doi:10.1016/S0007-8506(07)62412-3.

Tryson M and Kiil H-E (2010) Dielectric Electro Active Polymers: Development of an Industry. In Proceedings of SPIE, 7642:76421X-1-76421X-9. doi:10.1117/12.848729.

Uddin A, Khan MK, Campean F et al. (2016) A framework for complex product architecture analysis using an integrated approach. Concurrent Engineering 24 (3): 195-210. doi:10.1177/1063293X16647434.

Ulrich KT and Eppinger SD (2008) Product Design and Development. 4th ed. McGraw-Hill. 
Vermaas PE (2013) The Coexistence of Engineering Meanings of Function: Four Responses and Their Methodological Implications. Artificial Intelligence for Engineering Design, Analysis and Manufacturing 27 (03): 191-202. doi:10.1017/S0890060413000206.

Vojak BA and Chambers FA (2004) Roadmapping Disruptive Technical Threats and Opportunities in Complex, Technology-Based Subsystems: The SAILS Methodology. Technological Forecasting and Social Change 71 (1-2): 121-139. doi:10.1016/S0040-1625(03)00047-7.

Walsh ST (2004) Roadmapping a Disruptive Technology: A Case Study The Emerging Microsystems and Top-down Nanosystems Industry. Technological Forecasting and Social Change 71 (1-2): 161-185. doi:10.1016/j.techfore.2003.10.003.

Ward MJ, Halliday ST and Foden J (2012) A readiness level approach to manufacturing technology development in the aerospace sector: and industrial approach. Proceedings of the Institution of Mechanical Engineers, Part B: Journal of Engineering Manufacture 226 (3): 547-552

Weber C (2005) CPM / PDD - An Extended Theoretical Appraoch to Modelling Products and Product Development Processes. In Proceedings of the 2nd German-Israeli Symposium on Advances in Methods and Systems for Development of Products and Processes, edited by H. Bley, H. Jansen, F.L. Krause, and M. Shpitalni, 159-179. Fraunhofer-IRB-Verlag.

Weber C and Deubel T (2003) New Theory-Based Concepts for PDM and PLM. Proceedings of ICED, 14th International Conference on Engineering Design. Stockholm.

Williamson R and Beasley J (2011) Automotive Technology and Manufacturing Readiness Levels - A guide to recognised stages of development within the Automotive Industry.

Wonglimpiyarat J (2004) The Use of Strategies in Managing Technological Innovation. European Journal of Innovation Management 7 (3): 229-250. doi:10.1108/14601060410549919.

Wood SC and Brown GS (1998) Commercializing Nascent Technology: The Case of Laser Diodes at Sony. Journal of Product Innovation Management 15 (2): 167-183. doi:http://dx.doi.org/10.1016/S07376782(97)00076-3.

Zurcher R and Kostoff RN (1997) Modeling Technology Roadmaps. The Journal of Technology Transfer 22 (3): 73-79. doi:10.1007/BF02509165. 


\section{BIOGRAPHIES}

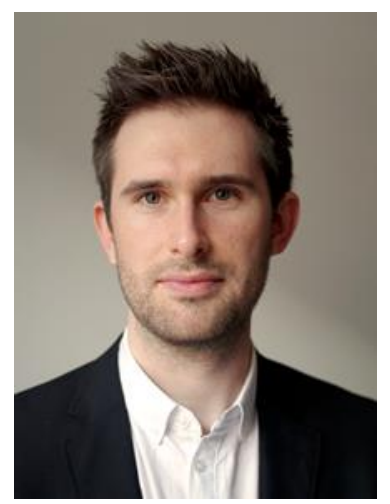

Poul Martin Ravn holds a PhD from the Section of Engineering Design and Product Development in the Mechanical Engineering Department at the Technical University of Denmark (DTU). His current research is focused on product architectures and multi-product integration in conjunction with technology development.

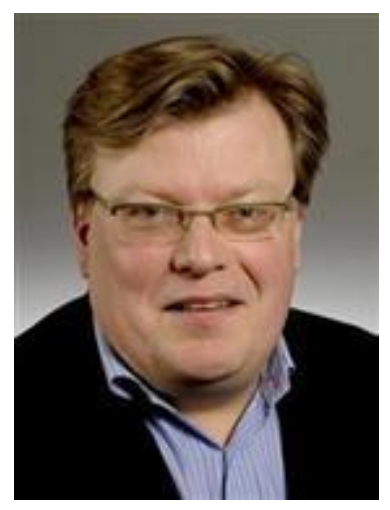

Niels Henrik Mortensen holds a PhD and an MSc in Mechanical Engineering and is employed as a Professor at the Technical University of Denmark. He is head of the section of Engineering Design and Product Development at DTU Mechanical Engineering at the Technical University of Denmark. His main research focus is procedures and methods supporting development of Product Families based on Architectures and Platforms. Currently there are 9 researchers within the field of architecture based product development. 


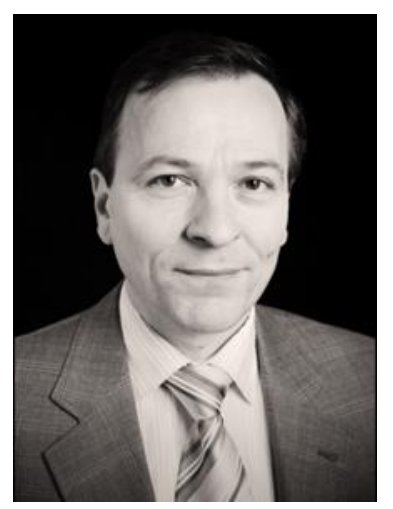

Lars Hvam holds a PhD and an MSc in Engineering and is a Professor in Operations Management at the Technical University of Denmark. His main research focus is product configuration, complexity management, and product modeling. Lars Hvam is currently managing a group of 7 researchers within this research field. 


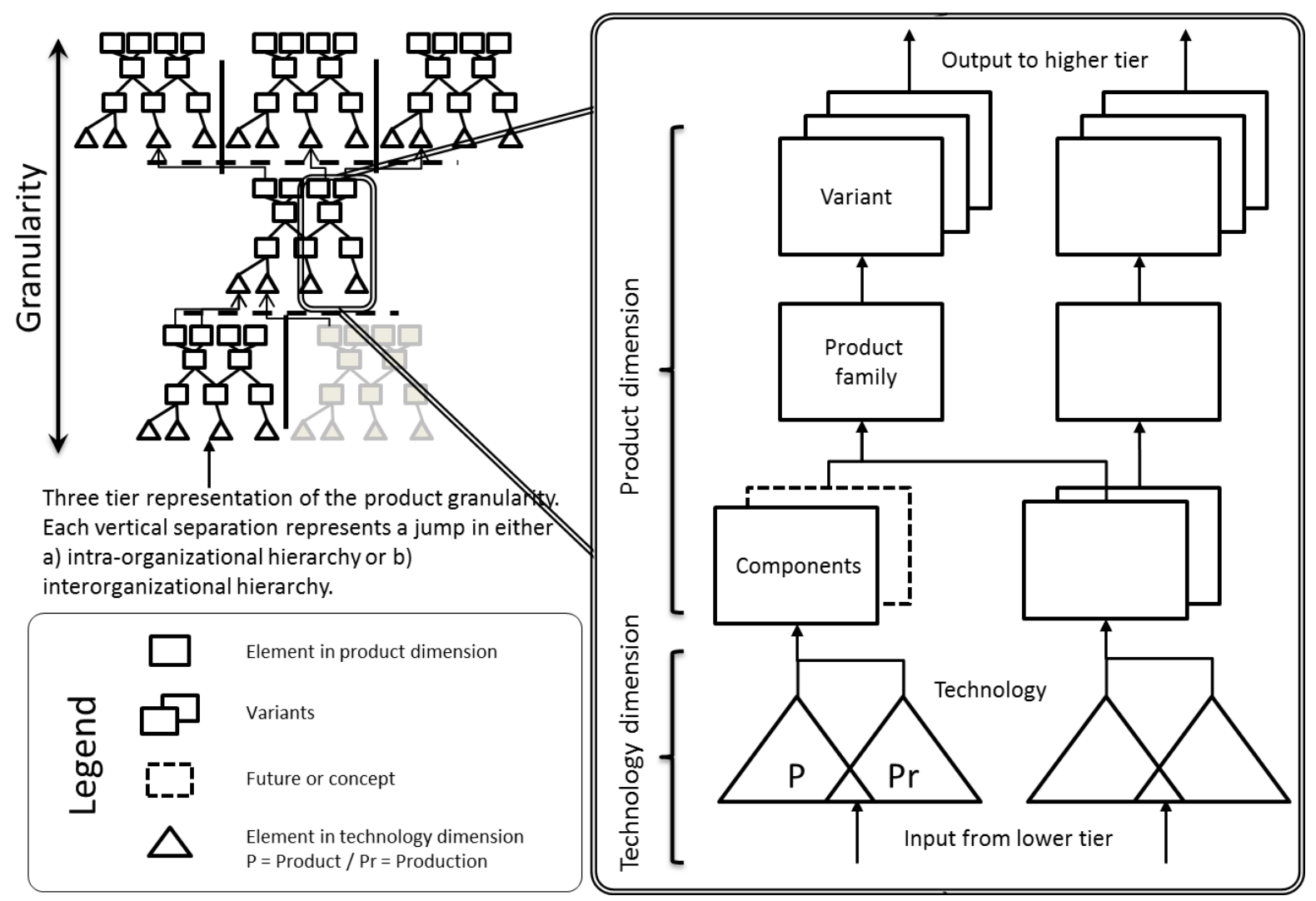

Figure 1. The structural part of the system. A representation of a product decomposition in four tiers each in four levels: technology, component, product family, and product variant. 


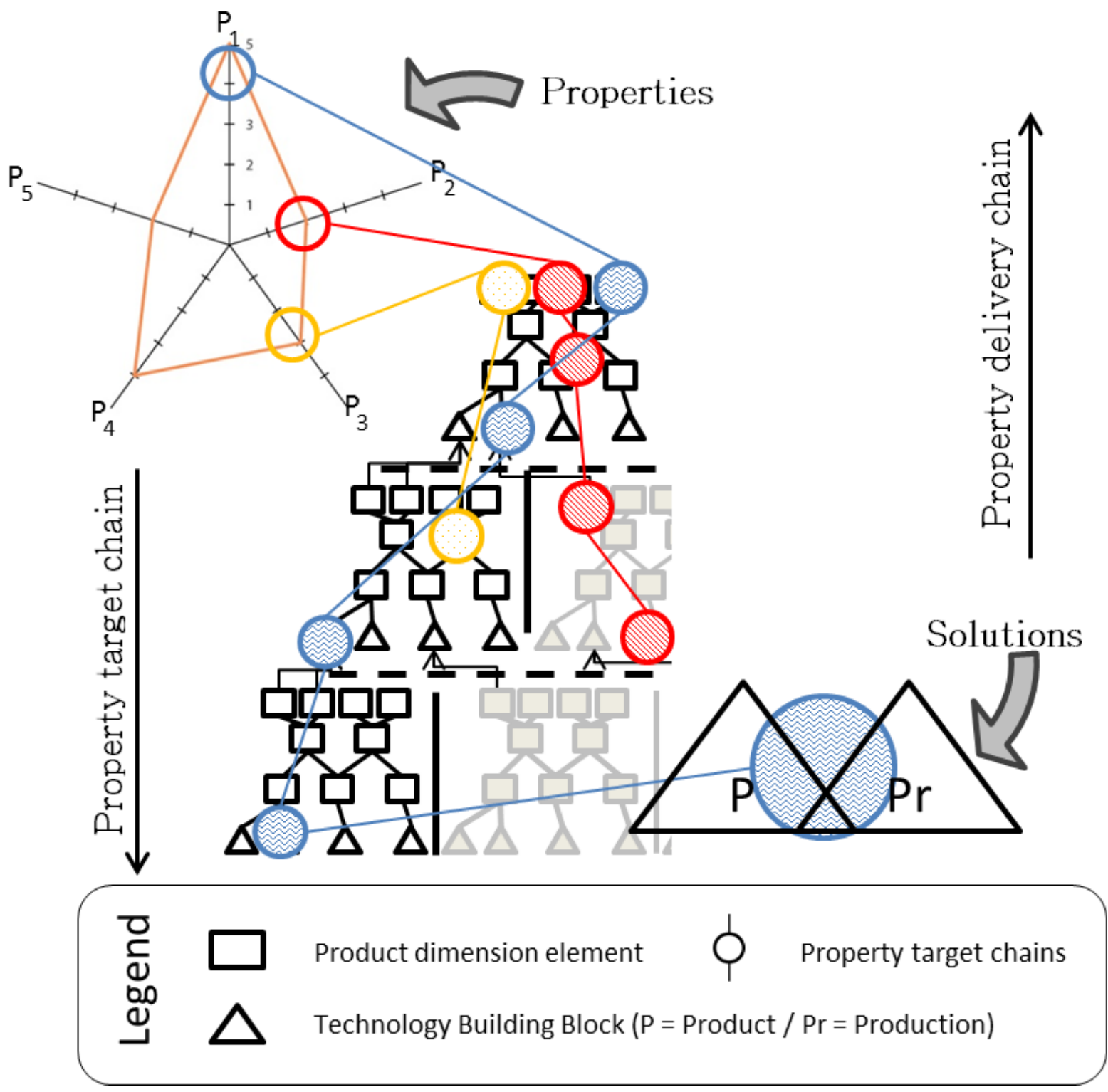

Figure 2. Two types of property relation chains A) Property target chain (top-down) B) Property delivery chain (bottom-up). 




Figure 3. The technology focus framework exemplified with a badminton frame manufacturer. 


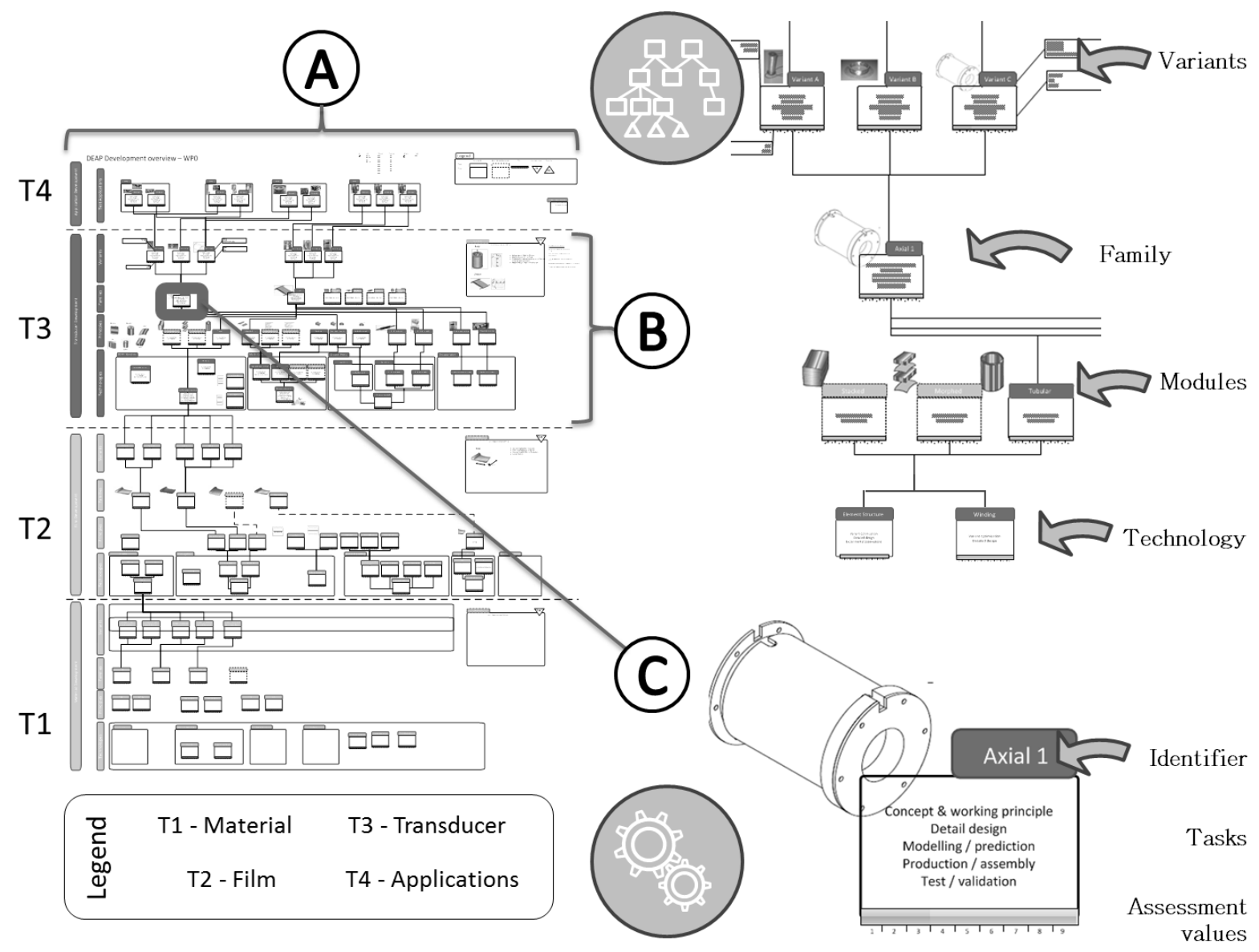

Figure 4. Example from the case: a) identification of structure on multiple levels, b) example of structure, and c) example of assessment. 


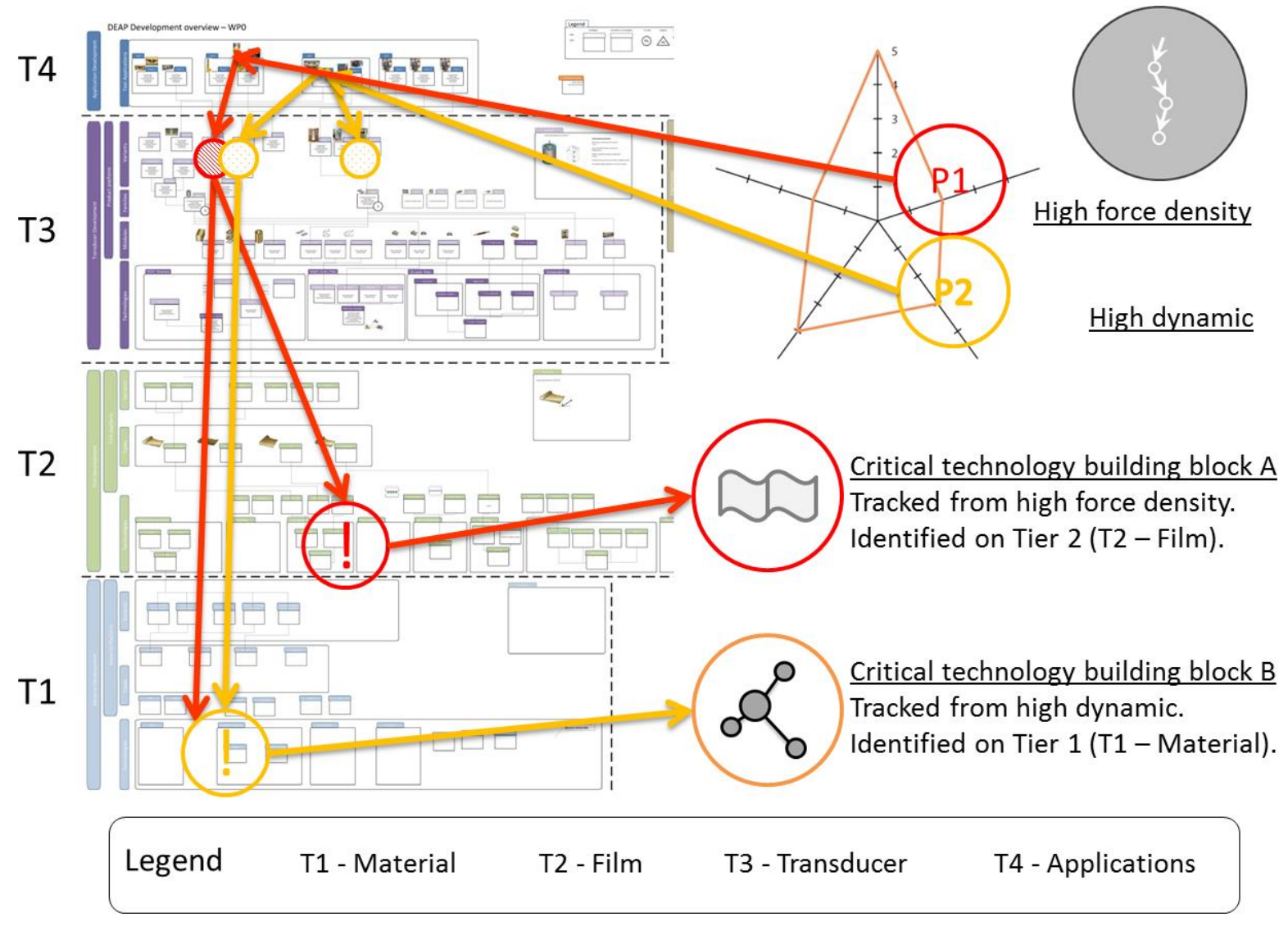

Figure 5. Identification of two critical technology building blocks. 
Table 1. The three steps of the framework and their inputs and outputs.

\begin{tabular}{lll}
\hline Step & Input & Output \\
\hline Overview & $\begin{array}{l}\text { Technologies, components, product families, and variants } \\
\text { Existing and upcoming solutions }\end{array}$ & $\begin{array}{l}\text { Portfolio overview } \\
\text { Variant / family / component / technology relations }\end{array}$ \\
\hline Assessment & $\begin{array}{l}\text { Performance assessments } \\
\text { Completed tasks }\end{array}$ & Current development status \\
\hline Reasoning & Identified key properties & $\begin{array}{l}\text { Next step of development through the identification } \\
\text { of Critical Technology Building Blocks }\end{array}$ \\
\hline
\end{tabular}

Table 2. Technology assessment metrics

\begin{tabular}{lll}
\hline Metric & Scale & Description \\
\hline TRL & $1-9$ & Standard measure of the maturity level of a technology (Mankins, 2009a) \\
\hline TNV & $1-5$ & Weighting factor based on the assessed importance of a particular technology development (Mankins, 2009a) \\
\hline R\&D & $1-5$ & The expected probability of success or failure for a given set of technology objectives (Mankins, 2009a) \\
\hline IRL & $1-9$ & Integration maturity metric for consistent comparison between integration points (Sauser et al., 2008) \\
\hline SRL & $0,10-$ & Normalized measure of system maturity utilizing TRL and IRL (Sauser et al., 2008) \\
& 1,00 & \\
\hline MRL & $1-10$ & Manufacturing maturity and risk assessment (OSD Manufacturing Technology Program, 2015) \\
\hline MCRL & $1-9$ & Manufacturing assessment directly related 1:1 to TRL scale (Ward et al., 2012) \\
\hline
\end{tabular}

